Virginia Commonwealth University VCU Scholars Compass

1999

\title{
Does N-2(-) exist? A coupled-cluster study
}

Gennady L. Gutsev

University of Florida

Piotr B. Rozyczko

University of Florida

RodneyJ. Bartlett

University of Florida

Charles A. Weatherford

Florida A $\mathrm{m}$ M University

Follow this and additional works at: http://scholarscompass.vcu.edu/phys_pubs

Part of the Physics Commons

Gutsev, G. L., Rozyczko, P. B., Bartlett, C. A., et al. Does N-2(-) exist? A coupled-cluster study. The Journal of Chemical Physics 110, 5137 (1999). Copyright @ 1999 AIP Publishing LLC.

\section{Downloaded from}

http://scholarscompass.vcu.edu/phys_pubs/146

This Article is brought to you for free and open access by the Dept. of Physics at VCU Scholars Compass. It has been accepted for inclusion in Physics Publications by an authorized administrator of VCU Scholars Compass. For more information, please contact libcompass@vcu.edu. 


\title{
Does $\mathbf{N}_{\mathbf{2}}^{-}$exist? A coupled-cluster study
}

\author{
Gennady L. Gutsev, ${ }^{\text {a) }}$ Piotr B. Rozyczko, and Rodney J. Bartlett \\ Quantum Theory Project, P.O. Box 118435, University of Florida, Gainesville, Florida 32611
}

Charles A. Weatherford

Department of Physics, Florida A\&M University, Tallahassee, Florida 32307

(Received 24 April 1997; accepted 10 December 1998)

\begin{abstract}
Potential energy curves of the ground-state $\mathrm{N}_{2}$ molecule and its doublet $\mathrm{N}_{2}^{-}$anion are calculated at the coupled-cluster level with single and double excitations and with noniterative triples [CCSD(T)] as well as with the multireference averaged-quadratic coupled-cluster (MR-AQCC) method. The $\mathrm{N}_{2}^{-}$ anion is shown to be temporary and decays to its neutral parent plus a free electron at bond lengths shorter than $\approx 1.4$ and larger than $\approx 2.5 \AA$. Thus, the $\mathrm{N}_{2}^{-}$anion exists within the $1.4 \leqslant R(\mathrm{~N}-\mathrm{N})$ $\leqslant 2.5 \AA$ range at the Born-Oppenheimer approximation. (C) 1999 American Institute of Physics.

[S0021-9606(99)00511-5]
\end{abstract}

\section{INTRODUCTION}

It is well known that $\mathrm{N}_{2}$ forms only temporary anion states following the interaction with incident electrons. ${ }^{1}$ The nature of these temporary states, also referred to as compound or resonance states, has been the subject of numerous experimental and theoretical efforts. ${ }^{2}$ It is generally believed ${ }^{1}$ that a temporary $\mathrm{N}_{2}^{-}\left({ }^{2} \Pi_{g}\right)$ state is responsible for lowenergy resonances observed in scattering experiments. The nature of these resonances has been studied experimentally ${ }^{1,2}$ and theoretically, both in the gas phase $\mathrm{s}^{3,4}$ and as adsorbates. ${ }^{5}$

A proper theoretical description of this temporary state appears to be complicated, since accurate calculations even for the ground-state potential energy surfaces (PEC) of $\mathrm{N}_{2}$ present a problem due to the dissociation of the triply bonded molecule to nitrogen atoms in their high-spin ${ }^{4} S$ ground states. Generally, a correct reproduction of the whole PEC in such a case typically requires the use of multiconfiguration $(\mathrm{MC})^{6,7}$ or multireference (MR) wave functions ${ }^{8-10}$ in order to account for the static correlation.

However, it was shown ${ }^{11}$ that the more economical single-reference coupled-cluster approach is capable of close reproduction of the multireference configuration interaction (MRCI) results for stretches of the $R(\mathrm{~N}-\mathrm{N})$ bond length up to $\approx 2 R_{e}$, where the dynamical correlation is more important.

The PEC of the $\mathrm{N}_{2}^{-}\left({ }^{2} \Pi_{g}\right)$ state was computed in the vicinity of the neutral equilibrium bond length both at the Hartree-Fock (HF) ${ }^{12-14}$ and MRCI ${ }^{15}$ levels. These calculations have found an intersection point of the neutral and anion PECs, which indicates the formation of a $\mathrm{N}_{2}^{-}$state stable with respect to vertical detachment of an extra electron. Recently, Gianturco and Schneider ${ }^{16}$ have performed MRCI calculations on the $\mathrm{N}_{2}-\mathrm{N}_{2}^{-}$pair with a $12 s 7 p / 6 s 4 p$ basis set augmented with two $d$-functions and one diffuse $s p$-shell. They found a bound portion of the $\mathrm{N}_{2}^{-}$curve at $1.48 \leqslant R(\mathrm{~N}-\mathrm{N}) \leqslant 2.65 \AA$, but were not able to reproduce the

${ }^{a}$ Present address: Physics Department, Virginia Commonwealth University, Richmond, VA 23284-2000. autodetaching area of $\mathrm{N}_{2}^{-}$because this requires an inclusion of very diffuse functions into standard basis sets. ${ }^{17}$

The main purpose of the present work is to construct the $\mathrm{N}_{2}^{-}\left({ }^{2} \Pi_{g}\right)$ PEC at the coupled-cluster level of theory with a large atomic natural orbital basis augmented with diffuse $s p d$-shells. Our preliminary results for $\mathrm{H}_{2}-\mathrm{H}_{2}^{-}$and $\mathrm{N}_{2}-\mathrm{N}_{2}^{-}$ PECs and the results of other calculations for the $\mathrm{H}_{2}-\mathrm{H}_{2}^{-18}$ and $\mathrm{HCl}-\mathrm{HCl}^{-} \mathrm{PECs}^{19}$ have shown some continuation of the anion curves beyond the intersection point to the shorter bond-length region, where the anions should decay to their neutral parents and a free electron. Such continuations appear to be due to the use of finite basis sets and should not show up if a near-infinite basis is employed.

\section{COMPUTATIONAL DETAILS}

Our calculations have been performed with the ACES II suite of programs ${ }^{20}$ at the coupled-cluster level with single and double excitations $(\mathrm{CCSD})^{21}$ and noniterative $[\operatorname{CCSD}(\mathrm{T})]^{22,23}$ inclusion of triple excitations. For the $\mathrm{N}_{2}$ and $\mathrm{N}_{2}^{-}$systems at $R(\mathrm{~N}-\mathrm{N})=1.7$ and $1.9 \AA$, we employed two multireference methods, multiconfiguration self-consistent field (MC-SCF) and a variation of multireference configura-

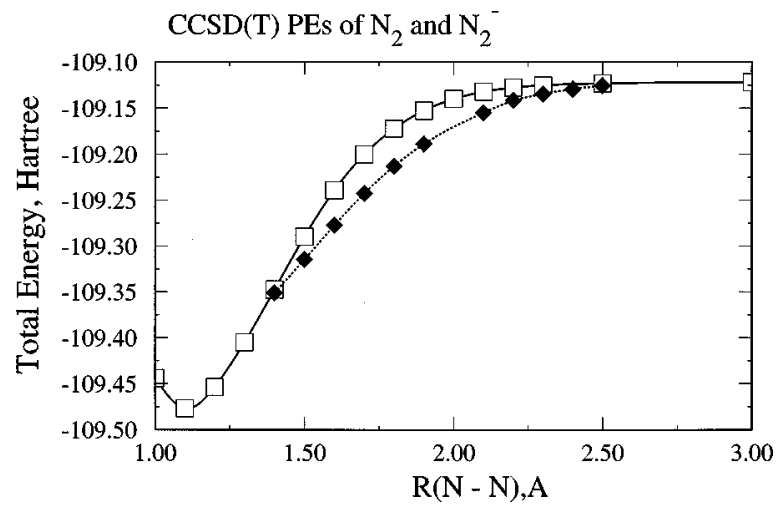

FIG. 1. $\operatorname{CCSD}(\mathrm{T})$ potential energy curves of $\mathrm{N}_{2}\left(X^{1} \Sigma_{g}^{+}\right)$and $\mathrm{N}_{2}^{-}\left({ }^{2} \Pi_{g}\right)$ : the neutral molecule - open boxes, solid line; the anion—solid boxes, dotted line. 
TABLE I. Convergence of the total and orbital energies as well as the bond length of $\mathrm{N}_{2}^{-}\left({ }^{2} \Pi_{g}\right)$ when decreasing the exponent $(\zeta)$ of an $s p d$-shell, sited at the middle of the $\mathrm{N}-\mathrm{N}$ bond. Calculations are carried out at the CCSD+T(CCSD) (Ref. 23) level of theory. Bond length is in $\AA$, total and orbital energies are in hartree.

\begin{tabular}{lcccrc}
\hline \multicolumn{1}{c}{ Property } & \multicolumn{2}{c}{$\mathrm{N}_{2}^{-},{ }^{2} \Pi_{g}$} & $\mathrm{~N}_{2}, X^{1} \Sigma_{g}^{+}$ \\
\hline & $\mathrm{WMR}^{\mathrm{a}}$ & $\zeta=0.005$ & $\zeta=0.0005$ & $\zeta=0.00005$ & $\mathrm{WMR}$ \\
$R(\mathrm{~N}-\mathrm{N})$ & 1.16484 & 1.099347 & 1.09935 & 1.09928 & 1.09931 \\
$E(\mathrm{HF})$ & -108.896380 & -108.974597 & -108.989997 & -108.991566 & -108.991948 \\
$E(\mathrm{CCSD})$ & -109.379881 & -109.438332 & -109.453850 & -109.455379 & -109.455598 \\
$E(\mathrm{CCSD}+\mathrm{T})$ & -109.404934 & -109.460351 & -109.475855 & -109.477431 & -109.477606 \\
$\epsilon_{\text {Ххмо }}$ & 0.02466 & 0.01734 & 0.00175 & 0.00018 & 0.05988 \\
\hline \hline
\end{tabular}

${ }^{a}$ The smallest $p$-exponent is 0.034 in this basis set.

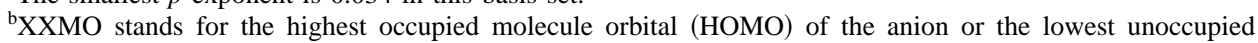
molecular orbital (LUMO) of the neutral molecule.

tion interaction method with singles and doubles (MR-CISD) corrected partially for size-extensivity, namely, multireference averaged-quadratic coupled-cluster (MR-AQCC) ${ }^{24}$ as implemented in the COLUMBUS ${ }^{25}$ suite of programs. This method provides accuracy similar to the averaged coupledpair functional (ACPF) method, but can be successfully used with a much smaller active space. ${ }^{24}$ The active space consists of six electrons (seven for $\mathrm{N}_{2}^{-}$) in six orbitals (seven for $\mathrm{N}_{2}^{-}$) and the $3 \sigma_{g}$ and $1 \pi_{u}$ molecular orbitals (MOs) and the $2 \pi_{g}$ and $4 \sigma_{u}$ MOs were selected as valence holes and valence particles for $\mathrm{N}_{2}$, respectively. The occupied $\sigma_{g}$ MO was added into the active space of the anion.

The large atomic natural orbital basis of Widmark-Malmqvist-Roos ${ }^{26}$ (WMR) described as ( $14 s 9 p 4 d 3 f / 7 s 7 p 4 d 3 f$ ) was used in calculations of the $\mathrm{N}_{2}$ and bound portion of $\mathrm{N}_{2}^{-}$PECs. In order to allow the simulation of an extra electron autodetachment from $\mathrm{N}_{2}^{-}$, the basis was augmented by diffuse $s p$-shells ${ }^{27}$ located at the middle point of bonds. Adding a diffuse set practically does not influence the total energies of the bound states but allows the extra electron to move into the most diffuse MO of the "anion" (which corresponds in such a case to decay into the neutral system and a free electron) if the neutral parent cannot sustain the extra electron.

\section{RESULTS AND DISCUSSION}

Let us consider first the results of our $\operatorname{CCSD}(\mathrm{T}) / \mathrm{WMR}$ calculations for the ground state of $\mathrm{N}_{2}$. Our computed bond length and vibrational frequency, $1.0984 \AA$ and $2356.1 \mathrm{~cm}^{-1}$, respectively, are in nice agreement with experimental 1.0977 $\AA$ and $2358.6 \mathrm{~cm}^{-1},{ }^{28}$ correspondingly. Since the $\operatorname{CCSD}(\mathrm{T})$ method is size extensive, the dissociation energy $\left(D_{e}\right)$ of $\mathrm{N}_{2}$ $\left(X^{1} \Sigma_{g}^{+}\right)$, calculated either as the difference in the total energies of the ground-state molecule and two isolated nitrogen atoms, or as the difference in the total energies at the equilibrium bond length and at $R(\mathrm{~N}-\mathrm{N})=30$ a.u. (the state is ${ }^{7} \Sigma_{u}^{+}$), is $9.67 \mathrm{eV}$ and is close to the MRCI results ${ }^{9,10} \mathrm{ob}-$ tained with the bases of comparable quality. The ${ }^{2} \Pi_{g}$ state of $\mathrm{N}_{2}^{-}$is unstable by $\approx 2.0 \mathrm{eV}$ with respect to the ground state of $\mathrm{N}_{2}$; therefore, an extra electron cannot be attached in order to form a thermodynamically stable anion state.

Since the $\mathrm{N}_{2}^{-}\left({ }^{2} \Pi_{g}\right)$ state is unbound in the vicinity of its WMR equilibrium bond length, let us consider the decay of this state to the neutral ground state plus a free electron as a function of the exponent of an $s p d$-shell added to the WMR basis set and placed at the middle of the $R(\mathrm{~N}-\mathrm{N})$ distance. The results of optimizations with the extended bases are presented in Table I, from where one can see a fast convergence of the total energy and bond length of $\mathrm{N}_{2}^{-}$to those of the neutral molecule upon decreasing the exponent. With the exponent of 0.00005 , the results for the anion practically match the results obtained for the neutral parent.

Figure 1 presents the PESs of $\mathrm{N}_{2}\left(X^{1} \Sigma_{g}^{+}\right)$and $\mathrm{N}_{2}^{-}\left({ }^{2} \Pi_{g}\right)$ obtained at the $\operatorname{CCSD}(\mathrm{T})$ level of theory with the WMR basis extended by seven diffuse $s p$-shells ${ }^{27}$ with the use of an unrestricted HF reference function. As is seen, the total energy of $\mathrm{N}_{2}^{-}$is below that of $\mathrm{N}_{2}$ at the bond lengths from $\approx 1.4$ to $\approx 2.5 \AA$. In order to confirm the existence of the temporary ${ }^{2} \Pi_{g}$ state of $\mathrm{N}_{2}^{-}$, we performed multireference highly correlated MR-AQCC calculations with the WMR basis at $R(\mathrm{~N}-\mathrm{N})=1.7$ and $1.9 \AA$, where $\mathrm{N}_{2}^{-}$was found to be bound at the $\operatorname{CCSD}(\mathrm{T}) / \mathrm{WMR}$ level. As shown by the entries of Table II, the $\mathrm{N}_{2}^{-}$anion is below the energy of $\mathrm{N}_{2}$.

The very existence of temporary $\mathrm{N}_{2}^{-}$, which is electronically bound at the bond lengths from $\approx 1.4$ to $\approx 2.5 \AA$, has to be due to the polarization of two nitrogen atoms of the neutral $\mathrm{N}_{2}$ molecule by an extra electron in the opposite direction when the molecule is sufficiently excited to have the

TABLE II. Results of the calculations with the WMR basis for the neutral $\left(\mathrm{N}_{2}, X^{1} \Sigma_{g}^{+}\right)$and anion $\left(\mathrm{N}_{2}^{-},{ }^{2} \Pi_{g}\right)$ ground states at two internuclear separations of 1.7 and $1.9 \AA$. Total energies are in hartree, differences between the total energies $(\Delta E)$ are in $\mathrm{eV}$.

\begin{tabular}{lcccccc}
\hline \hline & \multicolumn{3}{c}{$R(\mathrm{~N}-\mathrm{N})=1.7 \AA$} & \multicolumn{3}{c}{$R(\mathrm{~N}-\mathrm{N})=1.9 \AA$} \\
\hline Level & $\mathrm{N}_{2}$ & $\mathrm{~N}_{2}^{-}$ & $\Delta E$ & $\mathrm{~N}_{2}$ & $\mathrm{~N}_{2}^{-}$ & $\Delta E$ \\
MR-SCF & -108.618160 & -108.702613 & 2.298 & -108.481845 & -108.600471 & 3.227 \\
MR-AQCC & -109.237938 & -109.247264 & 0.247 & -108.600471 & -109.149212 & 1.240 \\
\hline \hline
\end{tabular}


large amplitude of nuclear motions. At smaller and larger bond lengths, this state decays to the ground or vibrationally excited states of the neutral $\mathrm{N}_{2}$ molecules plus a free electron.

In conclusion, we would like to underline a unique character of the $\mathrm{N}_{2}^{-}$anion: it does not exist at short bond lengths because the neutral $\mathrm{N}_{2}$ molecule is not able to form a thermodynamically stable state. On the other hand, it does not exist at large bond lengths as well because the nitrogen atom has no positive electron affinity.

\section{ACKNOWLEDGMENT}

This work was supported by the Office of Naval Research Grant No. N00014-95-1-0614.

${ }^{1}$ G. J. Schulz, Rev. Mod. Phys. 45, 423 (1973).

${ }^{2}$ Resonances, edited by D. G. Truhlar (American Chemical Society, Washington, D.C., 1984).

${ }^{3}$ C. A. Weatherford and A. Temkin, Phys. Rev. A 49, 2580 (1994).

${ }^{4}$ W. Sun, M. A. Morrison, W. A. Isaacs, W. K. Trail, D. T. Alle, R. J. Gulley, M. J. Brennan, and S. J. Buckman, Phys. Rev. A 52, 1229 (1995).

${ }^{5}$ P. J. Rous, Surf. Sci. 326, 67 (1995).

${ }^{6}$ R. Rumble, Jr., W. J. Stevens, and D. G. Truhlar, J. Phys. B 17, 3151 (1984).

${ }^{7}$ C. A. Weatherford, F. B. Brown, and A. Temkin, Phys. Rev. A 35, 4561 (1987).

${ }^{8}$ J. Almlöf, B. J. DeLeeuw, P. R. Taylor, C. W. Bauschlicher, Jr., and P. Siegbahn, Int. J. Quantum Chem., Symp. 23, 345 (1989).

${ }^{9}$ H.-J. Werner and P. J. Knowles, J. Chem. Phys. 94, 1264 (1991).

${ }^{10}$ R. S. Grev and H. F. Schaefer, III, J. Chem. Phys. 96, 6850 (1992).
${ }^{11}$ R. J. Bartlett and J. F. Stanton, Reviews in Computational Chemistry, edited by K. B. Lipkowitz and D. B. Boyd (VCH, New York, 1994), Vol. 5, pp. 95-165.

${ }^{12}$ B. I. Schneider, M. Le Dourneuf, and V. K. Lan, Phys. Rev. Lett. 43, 1926 (1979).

${ }^{13}$ A. U. Hazi, T. N. Rescigno, and M. Kurilla, Phys. Rev. A 23, 1089 (1981).

${ }^{14}$ P. G. Burke, C. J. Noble, and S. Salvini, J. Phys. B 16, L113 (1983).

${ }^{15}$ B. M. Nestmann and S. D. Peyerimhoff, J. Phys. B 18, 4309 (1985).

${ }^{16}$ F. A. Gianrurco and F. Scheider, J. Phys. B 29, 1175 (1996).

${ }^{17}$ G. L. Gutsev and L. Adamowicz, J. Chem. Phys. 102, 9309 (1995).

${ }^{18}$ C. W. McCurdy and R. C. Mowrey, Phys. Rev. A 25, 2529 (1982).

${ }^{19}$ M. Krauss and W. J. Stevens, J. Chem. Phys. 74, 570 (1981).

${ }^{20}$ ACES II is a program product of the Quantum Theory Project, University of Florida, J. F. Stanton, J. Gauss, J. D. Watts, M. Nooijen, N. Oliphant, S. A. Perera, P. G. Szalay, W. J. Lauderdale, S. R. Gwaltney, S. Beck, A. Balkova, D. E. Bernholdt, K.-K. Baeck, P. Rozyczko, H. Sekino, C. Huber, and R. J. Bartlett. Integral packages included are VMOL (J. Almlöf and P. R. Taylor), vprops (P. R. Taylor), and ABACUS (H. J. Helgaker, Aa. Jensen, P. Jørgensen, and P. R. Taylor).

${ }^{21}$ G. D. Purvis, III, and R. J. Bartlett, J. Chem. Phys. 76, 1910 (1982).

${ }^{22}$ M. Urban, J. Noga, S. J. Cole, and R. J. Bartlett, J. Chem. Phys. 83, 4041 (1985).

${ }^{23}$ R. J. Bartlett, J. D. Watts, S. A. Kucharski, and J. Noga, Chem. Phys. Lett. 165, 513 (1990).

${ }^{24}$ P. G. Szalay and R. J. Bartlett, Chem. Phys. Lett. 214, 481 (1993).

${ }^{25}$ R. Shepard, I. Shavitt, R. M. Pitzer, D. C. Comeau, M. Pepper, H. Lishka, P. G. Szalay, R. Ahlrichs, F. B. Brown, and J.-G. Zhao, Int. J. Quantum Chem. S22, 149 (1988).

${ }^{26}$ P. O. Widmark, P. A. Malmqvist, and B. O. Roos, Theor. Chim. Acta 77, 291 (1990).

${ }^{27}$ G. L. Gutsev and R. J. Bartlett, J. Chem. Phys. 105, 8785 (1996).

${ }^{28}$ K. P. Huber and G. Herzberg, Constants of Diatomic Molecules (Van Nostrand Reinhold, New York, 1979). 